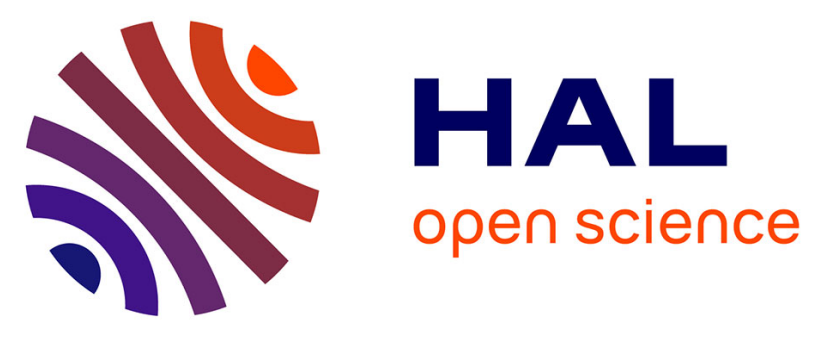

\title{
Anomalous Volume Changes in the Siliceous Zeolite Theta-1 TON due to Hydrogen Insertion under High-Pressure, High-Temperature Conditions
}

Damian Paliwoda, Davide Comboni, Tomasz Poręba, Michael Hanfland, Frederico Alabarse, David Maurin, Thierry Michel, Umit Demirci, Jérôme Rouquette, Francesco Di Renzo, et al.

\section{To cite this version:}

Damian Paliwoda, Davide Comboni, Tomasz Poręba, Michael Hanfland, Frederico Alabarse, et al.. Anomalous Volume Changes in the Siliceous Zeolite Theta-1 TON due to Hydrogen Insertion under High-Pressure, High-Temperature Conditions. Journal of Physical Chemistry Letters, 2021, 12 (21), pp.5059-5063. 10.1021/acs.jpclett.1c00965 . hal-03284608

\section{HAL Id: hal-03284608 \\ https://hal.umontpellier.fr/hal-03284608}

Submitted on 1 Oct 2021

HAL is a multi-disciplinary open access archive for the deposit and dissemination of scientific research documents, whether they are published or not. The documents may come from teaching and research institutions in France or abroad, or from public or private research centers.
L'archive ouverte pluridisciplinaire HAL, est destinée au dépôt et à la diffusion de documents scientifiques de niveau recherche, publiés ou non, émanant des établissements d'enseignement et de recherche français ou étrangers, des laboratoires publics ou privés. 


\section{Anomalous Volume Changes in the Siliceous}

\section{Zeolite Theta-1 TON due to Hydrogen Insertion}

\section{under High-Pressure, High-Temperature Conditions}

Damian Paliwoda ${ }^{*}+$, Davide Comboni ${ }^{\nabla}$, Tomasz Poręba ${ }^{\nabla}$, Michael Hanfland $^{\nabla}$, Frederico

Alabarsell, David Maurin ${ }^{\mathbf{}}$, Thierry Michel ${ }^{\mathbf{\Lambda}}$, Umit B. Demirci§, Jérôme Rouquette广†, Francesco di Renzo + , Arie van der Lee§, Samuel Bernard ${ }^{+}$, Julien Haines ${ }^{*}+$

$\dagger$ ICGM, CNRS, Université de Montpellier, ENSCM, Montpellier, France.

${ }^{\nabla}$ ESRF, Grenoble, France

"Elettra Sincrotrone Trieste, Trieste, Italy

^Laboratoire Charles Coulomb, UMR 5221 CNRS, Université de Montpellier, Montpellier, France.

§ IEM, UMR 5635 (CNRS-ENSCM-UM), Université de Montpellier, Montpellier, France.

${ }^{\ddagger}$ CNRS, IRCER, UMR 7315, University of Limoges, F-87000 Limoges, France 


\section{AUTHOR INFORMATION}

\section{Corresponding Authors}

*Damian Paliwoda

Damian.Paliwoda@gmail.com

*Julien Haines

Tel: +33467149349

Julien.Haines@umontpellier.fr 
ABSTRACT. High-pressure x-ray diffraction and Raman spectroscopy in a diamond anvil cell were used to study the insertion of the chemical hydrogen storage material, ammonia borane, in the one dimensional pores of the zeolite theta-1, TON. Heating of this material up to $300^{\circ} \mathrm{C}$ under pressures up to $5 \mathrm{GPa}$ resulted in the release of a significant amount of hydrogen due to the conversion of ammonia borane confined in the channels of TON and outside the zeolite to polyaminoborane and then polyiminoborane chains. The filling of TON with hydrogen resulted in much greater increase in unit cell volume than that corresponding to thermal expansion of normal compact inorganic solids. This process at high temperature is accompanied with a phase transition from collapsed high-pressure $P b n 2_{1}$ form to the more symmetric $C m c 21$ phase with expanded pores. This material has a high capacity for hydrogen adsorption under high-temperature, high-pressure conditions.

\section{TOC GRAPHICS}

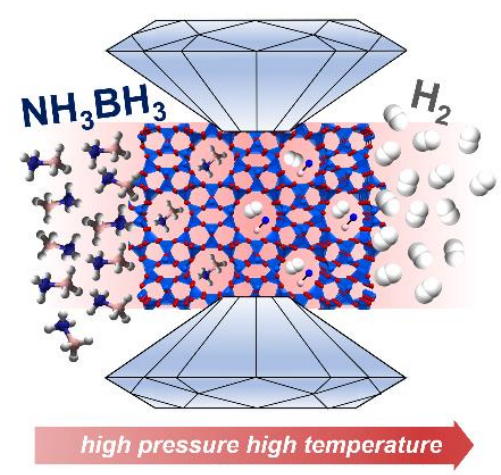

KEYWORDS. Ammonia borane, guest insertion, x-ray diffraction, high pressure, hydrogen. 
Ammonia borane is of great interest for chemical hydrogen storage as it has the highest releasable hydrogen content of $19.6 \mathrm{wt} . \%^{1-3}$. This hydrogen is released in several steps upon heating at relatively low temperature along with the polymerization of ammonia borane to form polyaminoborane and then polyiminoborane $e^{4-7}$. Porous scaffolds ${ }^{8-15}$, such as zeolites and metalorganic frameworks among others can, in principle, be used to modulate hydrogen release and eventually retain the hydrogen under conditions beyond the thermal stability conditions of ammonia borane. Ammonia borane with a Van der Waal's diameter of $3.8 \AA$ can be readily inserted in the microporous siliceous zeolite silicalite-1 with a MFI structure with a three-dimensional pore system with a diameter of $5.5 \AA$ at room temperature using moderate pressures ${ }^{16}$. In the present work, a model system with an even higher degree of confinement and one dimensional elliptical 5.5x4.7 ̊ pores was selected for pressure insertion of ammonia borane followed by hydrogen release and polymerization upon heating. This zeolite, theta-1 $\mathrm{TON}^{17}$ was found in previous work to be able to be filled with noble gases ${ }^{18}$ and to be used as a host for isolated 1-D polymer chains ${ }^{19}$ of polyacetylene and polycarbonyl.

Upon initial compression to $0.17 \mathrm{GPa}$ at ambient temperature, the initial mixture contained orthorhombic $\mathrm{TON}^{20}$ and tetragonal ammonia borane ${ }^{21}$, Figure 1 . The unit cell volume of TON was found to be only $0.06 \%$ lower than that at ambient pressure, Figure 2 and Table S1 in SI. The observed volume is higher than that expected for empty TON by $1 \%$ at the same pressure. This is consistent with previous work on silicalite-1, in which ammonia borane was found to be readily inserted on compression at room temperature ${ }^{16}$. The crystal structure of ammonia borane-filled TON was refined by the Rietveld method, Figure 3, Tables S1 - S3 and CIF file in SI. The most probable sites for the $\mathrm{B}$ and $\mathrm{N}$ atoms of $\mathrm{NH}_{3} \mathrm{BH}_{3}$ were located using Fourier difference maps. During the refinement, as no direct indication for ordering of $\mathrm{B}$ and $\mathrm{N}$ was found, the $\mathrm{BH}_{3}$ and 
$\mathrm{NH}_{3}$ groups were modelled with isoelectronic, dummy $\mathrm{F}$ atoms. Soft distance and angle constraints were applied to the TON framework as in previous work in which the same structural model ${ }^{18,20}$ was used. The B-N distance was constrained to $1.55 \AA$. The refined site occupation factor of the guests was found to be $0.28(2)$. This corresponds to $0.14(1) \mathrm{NH}_{3} \mathrm{BH}_{3}$ molecule per $\mathrm{SiO}_{2}$ unit, 1.2(1) $\mathrm{NH}_{3} \mathrm{BH}_{3}$ molecules per unit cell.
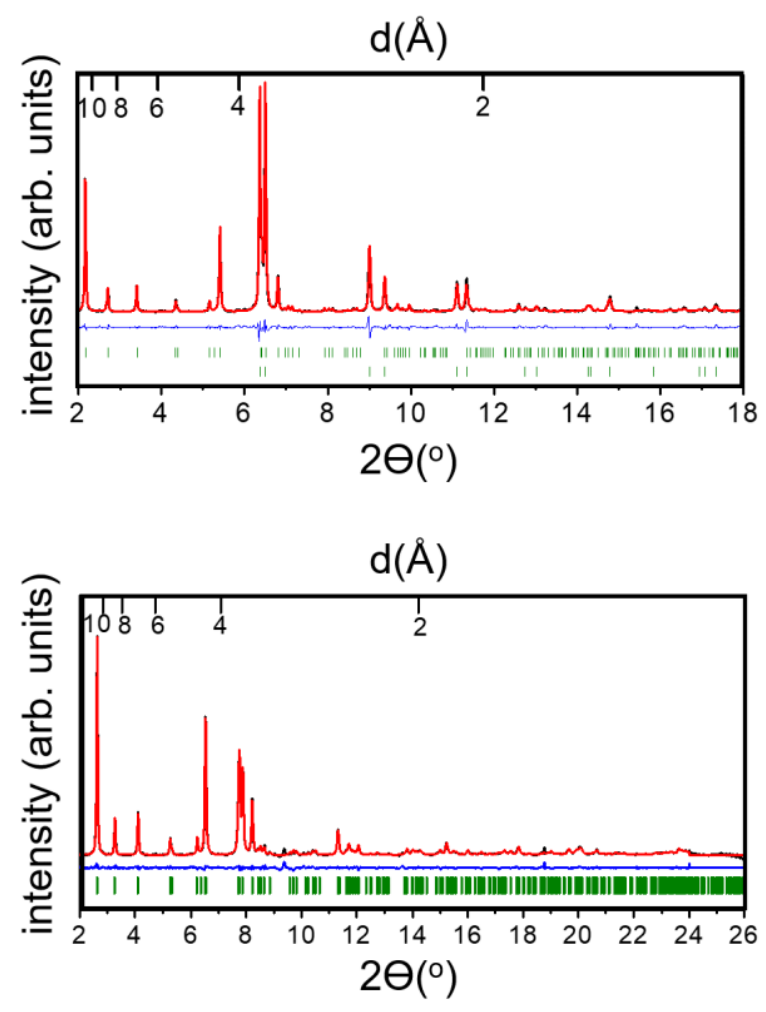

Figure 1. Experimental (black), calculated (red) and difference (blue) profiles ( $\lambda=0.4104 \AA$ ) for the $C m c 2_{1}$ structure of $\mathrm{TON}-\mathrm{NH}_{3} \mathrm{BH}_{3}(\lambda=0.4104 \AA)$ at $0.17 \mathrm{GPa}$ and $23^{\circ} \mathrm{C}$ (above) and TON-(BNH $))(\lambda=0.4957 \AA)$ recovered at ambient pressure and temperature after the experiment (below). Vertical bars indicate the calculated positions of the Bragg reflections. The lower row of markers in the top XRD pattern correspond to the tetragonal phase of 
$\mathrm{BH}_{3} \mathrm{NH}_{3}$, space group $\mathrm{I} 4 \mathrm{~mm}$. The strong background due to Compton scattering from the diamond is subtracted.

Upon compression from $0.17 \mathrm{GPa}$ to $2.8 \mathrm{GPa}$, a phase transition from the low pressure polymorph, space group $C m c 2_{1}$, to the high-pressure $P b n 2_{1}$ phase $^{20}$ was observed as in previous studies by the appearance of superlattice reflections indicating the loss of C-centering, $h k l, h+k \neq 2 n$. This phase transition, which occurs near 0.6 GPa in TON with empty pores in a non-penetrating, pressure transmitting medium, involves the partial collapse of the pores giving rise to an increase in ellipticity. The bulk ammonia borane was found to transform to the high pressure orthorhombic form ${ }^{21}$. The diffraction lines broaden strongly with compression due to the stiffening of the solid $\mathrm{NH}_{3} \mathrm{BH}_{3}$, thus only the unit cell parameters could be obtained. The unit cell volume is intermediate between empty $\mathrm{TON}^{20}$ and Nefilled $\mathrm{TON}^{18}$. The sample was then heated to $85^{\circ} \mathrm{C}$ and then to $128^{\circ} \mathrm{C}$ inducing an increase in pressure from 2.8 to over $4 \mathrm{GPa}$. Starting from $163^{\circ} \mathrm{C}$, the peaks of TON sharpen and those of ammonia borane disappear due to dehydrocoupling and polymerization of the latter. In parallel, a strong increase in volume is observed for TON amounting to $6 \%$ from $128^{\circ}$ to $195^{\circ} \mathrm{C}$. At close to $4 \mathrm{GPa}$, ammonia borane undergoes a phase transition above $120^{\circ} \mathrm{C}$ followed by dehydrocoupling and subsequent polymerization accompanied with hydrogen release beginning above $160^{\circ} \mathrm{C}^{7}$. The product polymer is polyaminoborane $\left(\mathrm{NH}_{2} \mathrm{BH}_{2}\right)_{n}$. Polymerization was confirmed by Raman spectroscopy on ammonia borane-filled TON upon heating, Figure 4 (see below). Such a significant volume increase cannot be due to the polymerization process in the pores as the polyaminoborane chains are much more compact than ammonia borane molecules. Thus, the most reasonable explanation for the large volume increase in TON, which is an order of magnitude greater than that expected from thermal expansion of a filled zeolite ${ }^{22}$, is the 
combination of the formation of hydrogen from the ammonia borane in the pores and the insertion of hydrogen formed due to polymerization of the bulk ammonia borane outside the TON crystallites.

It can be noted that at pressures close to $4 \mathrm{GPa}$, the next stage in hydrogen release with the formation of polyiminoborane $\left(\mathrm{BNH}_{\mathrm{x}}\right)_{\mathrm{n}}$ occurs at $220-230^{\circ} \mathrm{C}^{7}$. Heating over a small temperature interval from $235^{\circ} \mathrm{C}$ to $255^{\circ} \mathrm{C}$ results in a pressure drop from 3.5 to $1.9 \mathrm{GPa}$, a volume increase of $3.5 \%$, and retransformation of TON to the low pressure $C m c 2_{1}$ phase with expanded pores. The temperature was increased in two steps to $295^{\circ} \mathrm{C}$ with a further pressure drop to $1.1 \mathrm{GPa}$. The sample was held under these P-T conditions and the volume was found to further increase by 1.5 $\%$ after 90 minutes. This again can be associated with this release of hydrogen and insertion of hydrogen from the bulk polymer into TON, as discussed above.

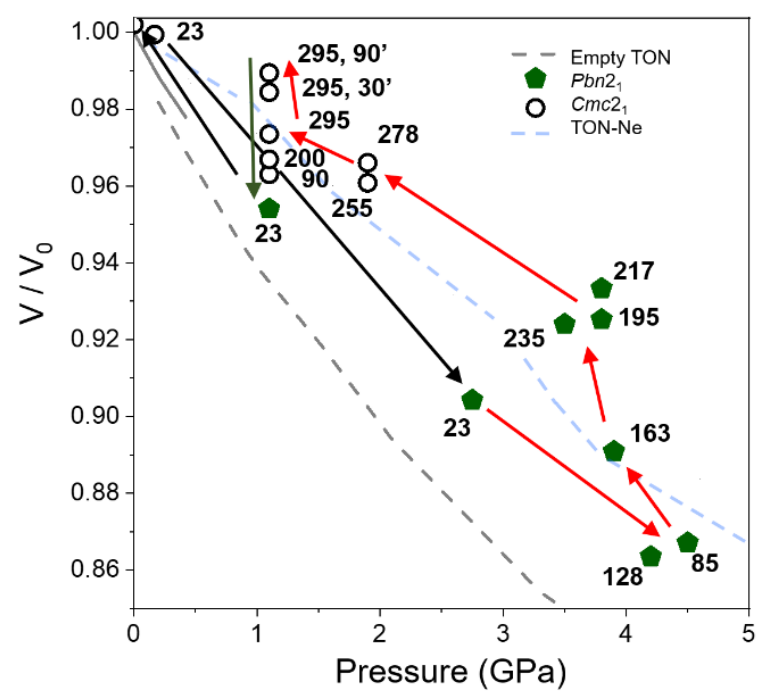

Figure 2. Relative volume of the TON - (B-N-H) system as a function of pressure. Temperatures are given in ${ }^{\circ} \mathrm{C}$. Arrows indicate the $\boldsymbol{P}$ - $\boldsymbol{T}$ path followed by the sample during 
its compression and decompression (arrows in black), heating (red arrows) and cooling (green arrow) cycles. Data for empty $\mathrm{TON}^{20}$ and Ne-filled TON ${ }^{18}$ are given for comparison.

Cooling from $295^{\circ} \mathrm{C}$ to $23^{\circ} \mathrm{C}$ at $1.1 \mathrm{GPa}$ resulted in a volume decrease of $3.7 \%$ and transition to the collapsed pore high-pressure $P b n 2_{1}$ phase below $90^{\circ} \mathrm{C}$. This thermal expansion/contraction, which is intermediate between that of a solid and a liquid, is much greater than that of polymerfilled zeolites ${ }^{22}$ and along with the partial pore collapse is evidence for a change in the volume or quantity of the hydrogen molecules in the pores.

On full pressure release in the recovered sample, TON was found to again retransform to the low pressure $C m c 2_{1}$ phase with expanded pores. The final unit cell volume was $1214.1(8) \AA^{3}$ directly after the experiment and 1207.1(5) $\AA^{3}$ several days later, which is slightly lower than that of the starting material ${ }^{20}, 1212.0 \AA^{3}$. This is an indication of complete release of hydrogen, which can be observed visually under microscope by the presence of gas bubbles in such samples. Fourier difference maps were again used to locate sites of electron density in the pores. The disordered $\mathrm{BH}$ and $\mathrm{NH}$ groups from the polyiminoborane were represented by isoelectronic dummy nitrogen atoms. Rietveld refinements were performed yielding 2(1) $\left(\mathrm{BNH}_{\mathrm{x}}\right)$ units per unit cell, Figure 3, Table S3 and CIF file in SI. 

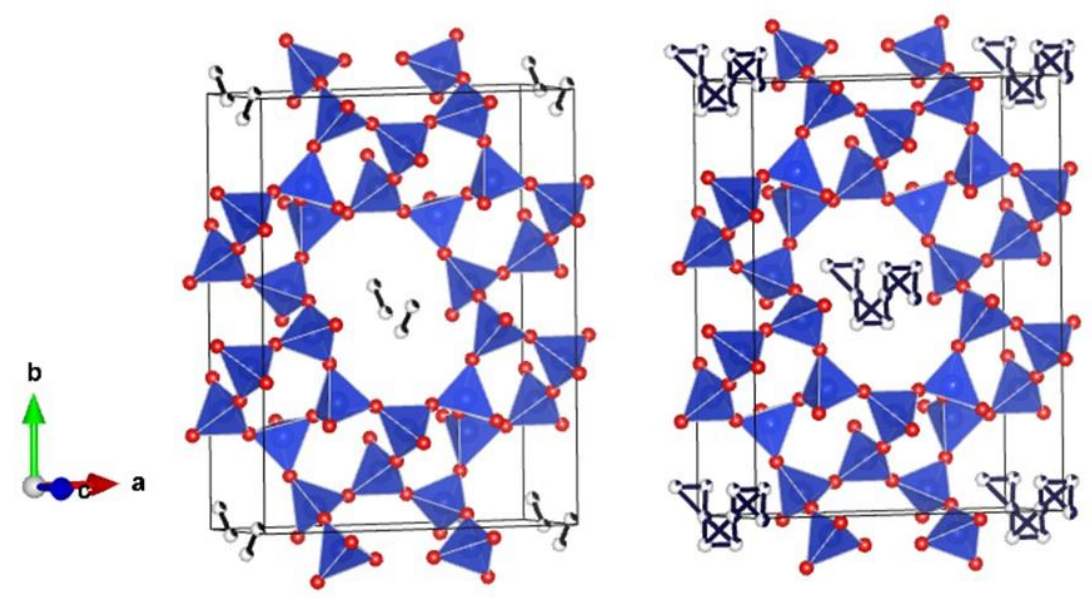

Figure 3. Crystal structures of $\mathrm{NH}_{3} \mathrm{BH}_{3}$-filled TON at $0.17 \mathrm{GPa}$ (left) and $\left(\mathrm{BNH}_{\mathrm{x}}\right)$-filled TON recovered at ambient pressure, (right). Partial occupancies are represented by shading.

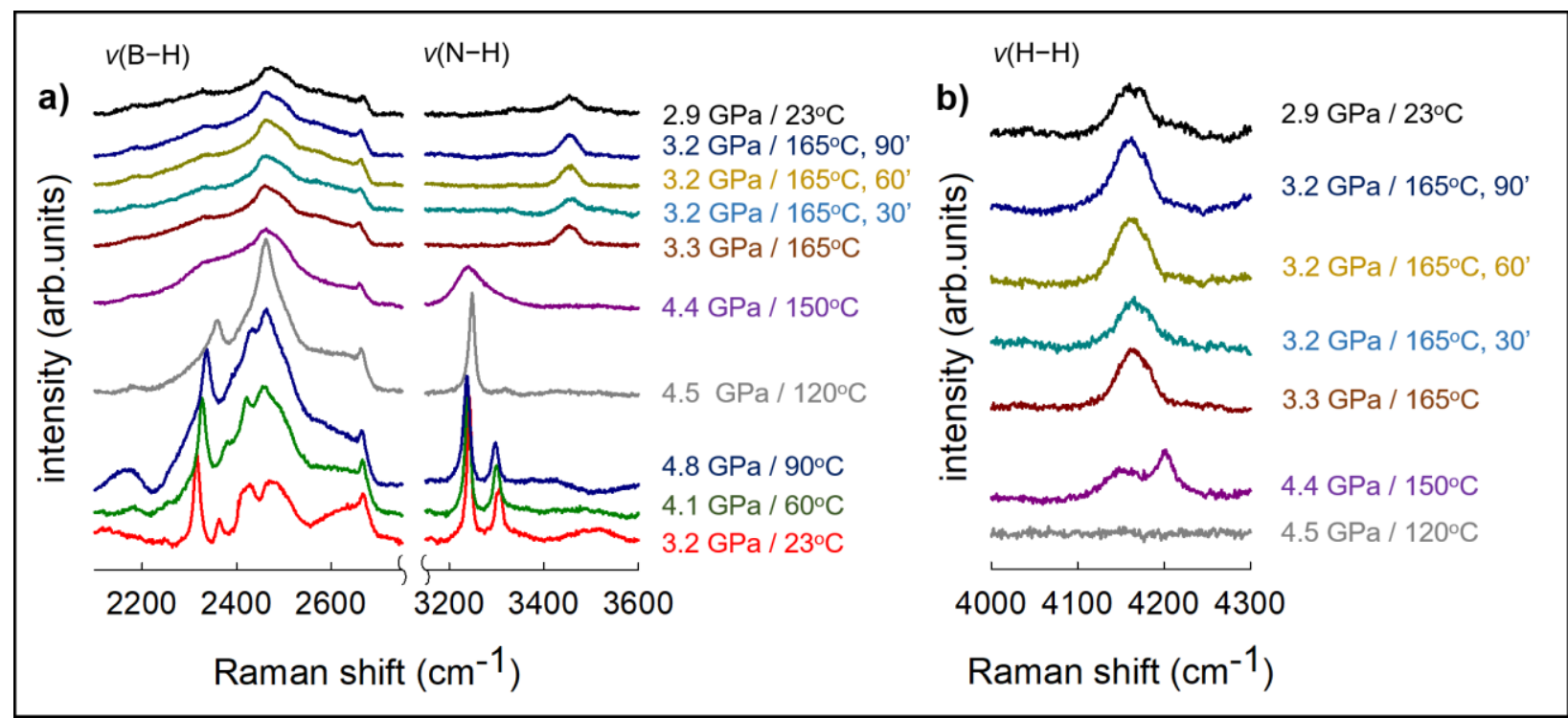

Figure 4. Raman spectra of the TON - (B-N-H) system as a function of pressure and temperature: $P, T$ - and time evolution of (a) the $\mathrm{B}-\mathrm{H}$ and $\mathrm{N}-\mathrm{H}$ stretching bands of ammonia borane, polyaminoborane and polyiminoborane, respectively and (b) fluid and absorbed hydrogen vibrons. Kinetic measurements were only possible in the lower pressure range near 
$3 \mathrm{GPa}$ as in the higher pressure range heating causes a strong pressure drop due to initial hydrogen release.

Raman spectroscopy was used to follow the polymerization and hydrogen release from an ammonia borane-TON sample, Figure 4. The sample was compressed to $3.2 \mathrm{GPa}$ and then heated. At $4.5 \mathrm{GPa}$ the high pressure, high temperature phase of ammonia borane was observed at $120^{\circ} \mathrm{C}$ with shifts to higher wavenumber for the main B-H and N-H stretching modes in agreement with previous work ${ }^{7,23-24}$. The hydrogen vibron appeared at $150^{\circ} \mathrm{C}$ and $4.4 \mathrm{GPa}$ along with the formation of polyaminoborane $\left(\mathrm{NH}_{2} \mathrm{BH}_{2}\right)_{\mathrm{n}}$ with its broadened N-H stretching bands. The two hydrogen vibron modes at $4202 \mathrm{~cm}^{-1}$ and $4150 \mathrm{~cm}^{-1}$ correspond to fluid and adsorbed hydrogen, respectively ${ }^{7}$. We noticed significant pressure drop from $4.4 \mathrm{GPa}$ to $3.3 \mathrm{GPa}$ at $165^{\circ} \mathrm{C}$ accompanied with the second step of ammonia borane polymerization yielding polyiminoborane $\left(\mathrm{BNH}_{\mathrm{x}}\right)_{\mathrm{n}}$, with its characteristic N-H stretching vibration near $3450 \mathrm{~cm}^{-1}$, overlapping the peaks of fluid and absorbed hydrogen, and further hydrogen loss. Minor changes are observed for the weaker B-H stretching modes, in particular the weakening of the lower wavenumber contribution as in previous work ${ }^{7}$. These changes are consistent with previous work on ammonia borane by Raman spectroscopy ${ }^{7}$ except the final stage of hydrogen loss in the present case occurs at about $30^{\circ} \mathrm{C}$ below that reported previously at the same pressure.

The present work indicates the chemical hydrogen storage material ammonia borane can be readily inserted in the pores of TON at modest pressure and ambient temperature. Heating of ammonia borane under pressure yields polyaminoborane, followed by polyiminoborane with the simultaneous release of hydrogen. The hydrogen generated in this process leads to an anomalous increase in the unit cell volume of TON of an order of magnitude greater than that expected due 
to thermal expansion. TON thus has a significant capacity for hydrogen adsorption under high pressure, high temperature conditions.

Experimental Methods

Polycrystalline TON, synthesized as described previously ${ }^{25}$, along with purified ammonia borane were loaded in a resistively-heated diamond anvil cell under an inert atmosphere in a glove box. Ruby and, in addition for Raman experiments, samarium-doped strontium borate were used as pressure calibrants, respectively. In a further Raman experiment, in order not to have any contamination from the fluorescence peaks of the calibrants, the pressures were based on the positions of the Raman peaks of ammonia borane and hydrogen previously measured in experiments with one or both calibrants. The pressure was estimated from the shift in the ${ }^{7} \mathrm{D}_{0}-{ }^{5} \mathrm{~F}_{0}$ fluorescence line of samarium-doped strontium borate ${ }^{26-27}$ or in the $\mathrm{R}_{1}$ fluorescence line of ruby corrected for the sample temperature ${ }^{28-29}$. The temperature was measured with a thermocouple placed on the diamond anvil. Raman spectra were obtained on a Renishaw inVia Raman Microscope using a $633 \mathrm{~nm}$ He-Ne laser for excitation ( $9 \mathrm{~mW}$ on the top of the diamond anvil). The scatter light was collected through $\mathrm{x} 5$ objective $(\mathrm{NA}=0.12)$ using a backscattering configuration. X-ray diffraction measurements $(\lambda=0.4104 \mathrm{~A})$ under pressure using a $10 \mu \mathrm{m}$ diameter convergent monochromatic incident beam were performed on the ID15-b beamline at the European Synchrotron Radiation Facility (Grenoble, France) equipped with a Eiger2 9M CdTe (DECTRIS) detector at $300 \mathrm{~mm}$ from the sample. The recovered sample in the gasket was studied by X-ray diffraction $(\lambda=0.4957 \mathrm{~A})$ with an $80 \mu \mathrm{m}$ beam on the Xpress beamline equipped with a PILATUS3 S 6M (DECTRIS) detector at the Sincrotrone ELETTRA Trieste (Trieste, Italy). The XRD images 
were converted to 1-D diffraction profiles using Dioptas ${ }^{30}$. Rietveld refinements were performed using Fullprof ${ }^{31}$ and crystal structures plotted using Vesta $^{32}$.

\section{ASSOCIATED CONTENT}

\section{Supporting Information.}

The following files are available free of charge.

X-ray diffraction and Raman spectroscopic data, TON_AB_SI.pdf(PDF)

Crystallographic Information File, TON_AB_170MPa.cif

Crystallographic Information File, TON_BNHx.cif

\section{AUTHOR INFORMATION}

\section{Notes}

The manuscript was written through contributions of all authors. All authors have given approval to the final version of the manuscript. Any additional relevant notes should be placed here.

The authors declare no competing financial interests.

\section{ACKNOWLEDGMENTS}

We would like to thank Kevin Turani-I-Belloto for purifying the ammonia borane used in this study. We acknowledge funding from the Agence Nationale de la Recherche in the framework of the contract ANR-19-CE08-0016. The IR-Raman technological Platform of the Université de Montpellier is acknowledged for the Raman experiments.

\section{REFERENCES}

(1) Hamilton, C. W.; Baker, R. T.; Staubitz, A.; Manners, I. B-N Compounds for Chemical Hydrogen Storage. Chem. Soc. Rev. 2009, 38 (1), 279-293. 
(2) Staubitz, A.; Robertson, A. P. M.; Manners, I. Ammonia-Borane and Related Compounds as Dihydrogen Sources. Chem. Rev. 2010, 110 (7), 4079-4124.

(3) Moussa, G.; Moury, R.; Demirci, U. B.; Sener, T.; Miele, P. Boron-Based Hydrides for Chemical Hydrogen Storage. Int. J. Energ. Res. 2013, 37 (8), 825-842.

(4) Baitalow, F.; Baumann, J.; Wolf, G.; Jaenicke-Rossler, K.; Leitner, G. Thermal Decomposition of BN-H Compounds Investigated by Using Combined Thermoanalytical Methods. Thermochim. Acta 2002, $391(1-2), 159-168$.

(5) Baitalow, F.; Wolf, G.; Grolier, J. P. E.; Dan, F.; Randzio, S. L. Thermal Decomposition of AmmoniaBorane under Pressures up to 600 bar. Thermochim. Acta 2006, 445 (2), 121-125.

(6) Wolf, G.; Baumann, J.; Baitalow, F.; Hoffmann, F. P. Calorimetric Process Monitoring of Thermal Decomposition of B-N-H Compounds. Thermochim. Acta 2000, 343 (1-2), 19-25.

(7) Nylen, J.; Sato, T.; Soignard, E.; Yarger, J. L.; Stoyanov, E.; Haussermann, U. Thermal Decomposition of Ammonia Borane at High Pressures. J. Chem. Phys. 2009, 131 (10), 104506.

(8) Rosi, N. L.; Eckert, J.; Eddaoudi, M.; Vodak, D. T.; Kim, J.; O'Keeffe, M.; Yaghi, O. M. Hydrogen Storage in Microporous Metal-Organic Frameworks. Science 2003, 300 (5622), 1127-1129.

(9) Gutowska, A.; Li, L. Y.; Shin, Y. S.; Wang, C. M. M.; Li, X. H. S.; Linehan, J. C.; Smith, R. S.; Kay, B. D.; Schmid, B.; Shaw, W.; Gutowski, M.; Autrey, T. Nanoscaffold Mediates Hydrogen Release and the Reactivity of Ammonia Borane. Angew. Chem. Int. Ed. 2005, 44 (23), 3578-3582.

(10) Wang, L. Q.; Karkamkar, A.; Autrey, T.; Exarhos, G. J. Hyperpolarized Xe-129 NMR Investigation of Ammonia Borane in Mesoporous Silica. J. Phys. Chem. C 2009, 113 (16), 6485-6490.

(11) Paolone, A.; Palumbo, O.; Rispoli, P.; Cantelli, R.; Autrey, T.; Karkamkar, A. Absence of the Structural Phase Transition in Ammonia Borane Dispersed in Mesoporous Silica: Evidence of Novel Thermodynamic Properties. J. Phys. Chem. C 2009, 113 (24), 10319-10321. 
(12) Kim, H.; Karkamkar, A.; Autrey, T.; Chupas, P.; Proffen, T. Determination of Structure and Phase Transition of Light Element Nanocomposites in Mesoporous Silica: Case Study of $\mathrm{NH}_{3} \mathrm{BH}_{3}$ in MCM-41. J Am. Chem. Soc. 2009, 131 (38), 13749-13755.

(13) Li, Z. Y.; Zhu, G. S.; Lu, G. Q.; Qiu, S. L.; Yao, X. D. Ammonia Borane Confined by a Metal-Organic Framework for Chemical Hydrogen Storage: Enhancing Kinetics and Eliminating Ammonia. J. Am. Chem. Soc. 2010, 132 (5), 1490-1491.

(14) Nielsen, T. K.; Besenbacher, F.; Jensen, T. R. Nanoconfined Hydrides for Energy Storage. Nanoscale 2011, 3 (5), 2086-2098.

(15) Demirci, U. B. Ammonia Borane: An Extensively Studied, Though Not Yet Implemented, Hydrogen Carrier. Energies 2020, 13 (12), 3071.

(16) Richard, J.; Cid, S. L.; Rouquette, J.; van der Lee, A.; Bernard, S.; Haines, J. Pressure-Induced Insertion of Ammonia Borane in the Siliceous Zeolite, Silicalite-1F. J. Phys. Chem. C 2016, 120 (17), 93349340.

(17) Barri, S. A. I.; Smith, G. W.; White, D.; Young, D. Structure of Theta-1, the First Unidimensional Medium-Pore High-Silica Zeolite. Nature 1984, 312 (5994), 533-534.

(18) Thibaud, J. M.; Rouquette, J.; Dziubek, K.; Gorelli, F. A.; Santoro, M.; Garbarino, G.; Clement, S.; Cambon, O.; van der Lee, A.; Di Renzo, F.; Coasne, B.; Haines, J. Saturation, of the Siliceous Zeolite TON with Neon at High Pressure. J. Phys. Chem. C 2018, 122 (15), 8455-8460.

(19) Santoro, M.; Scelta, D.; Dziubek, K.; Ceppatelli, M.; Gorelli, F. A.; Bini, R.; Garbarino, G.; Thibaud, J.-M.; Di Renzo, F.; Cambon, O.; Hermet, P.; Rouquette, J.; van der Lee, A.; Haines, J. Synthesis of 1D Polymer/Zeolite Nanocomposites under High Pressure. Chem. Mater. 2016, 28 (11), 4065-4071.

(20) Thibaud, J. M.; Rouquette, J.; Hermet, P.; Dziubek, K.; Gorelli, F. A.; Santoro, M.; Garbarino, G.; Alabarse, F. G.; Cambon, O.; Di Renzo, F.; van der Lee, A.; Haines, J. High-Pressure Phase Transition, 
Pore Collapse, and Amorphization in the Siliceous 1D Zeolite, TON. J. Phys. Chem. C 2017, 121 (8), 42834292.

(21) Chen, J. H.; Couvy, H.; Liu, H. Z.; Drozd, V.; Daemen, L. L.; Zhao, Y. S.; Kao, C. C. In Situ X-ray Study of Ammonia Borane at High Pressures. Int. J. Hydrogen Energy 2010, 35 (20), 11064-11070.

(22) Santoro, M.; Gorelli, F. A.; Bini, R.; Haines, J.; van der Lee, A. High-Pressure Synthesis of a Polyethylene/Zeolite Nano-Composite Material. Nat. Commun. 2013, 4, 1557.

(23) Nylen, J.; Eriksson, L.; Benson, D.; Haussermann, U. Characterization of a High Pressure, High Temperature Modification of Ammonia Borane ( $\left.\mathrm{BH}_{3} \mathrm{NH}_{3}\right)$. J. Chem. Phys. 2013, 139 (5), 054507.

(24) Wang, L. C.; Duan, D. F.; Zhao, B.; Bao, K.; Yu, H. Y. Structural and Dynamic Properties of the High-Pressure, High-Temperature Phase of Solid Ammonia Borane. J. Phys. Chem. C 2019, 123 (11), 6326-6332.

(25) Di Renzo, F.; Remoué, F.; Massiani, P.; Fajula, F.; Figueras, F.; Thierry Des, C. Crystallization Kinetics of Zeolite TON. Zeolites 1991, 11 (6), 539-548.

(26) Lacam, A.; Chateau, C. High-Pressure Measurements at Moderate Temperatures in a Diamond Anvil Cell with a New Optical Sensor $-\mathrm{SrB}_{4} \mathrm{O}_{7}-\mathrm{Sm}^{2+}$. J. Appl. Phys. 1989, 66 (1), 366-372.

(27) Datchi, F.; LeToullec, R.; Loubeyre, P. Improved Calibration of the $\mathrm{SrB}_{4} \mathrm{O}_{7}: \mathrm{Sm}^{2+}$ Optical Pressure Gauge: Advantages at Very High Pressures and High Temperatures. J. Appl. Phys. 1997, 81 (8), 33333339.

(28) Datchi, F.; Dewaele, A.; Loubeyre, P.; Letoullec, R.; Le Godec, Y.; Canny, B. Optical Pressure Sensors for High-Pressure-High-Temperature Studies in a Diamond Anvil Cell. High Pressure Res. 2007, 27 (4), 447-463.

(29) Shen, G.; Wang, Y.; Dewaele, A.; Wu, C.; Fratanduono, D. E.; Eggert, J.; Klotz, S.; Dziubek, K. F.; Loubeyre, P.; Fat'yanov, O. V.; Asimow, P. D.; Mashimo, T.; Wentzcovitch, R. M. M.; Bass, J.; Bi, Y.; He, D.; Khishchenko, K. V.; Leinenweber, K.; Li, B.; Sakai, T.; Tsuchiya, T.; Shimizu, K.; Yamazaki, D.; 
Mezouar, M.; Grp, I. T. Toward an International Practical Pressure Scale: A Proposal for an IPPS Ruby Gauge (IPPS-Ruby2020). High Pressure Res. 2020, 40 (3), 299-314.

(30) Prescher, C.; Prakapenka, V. B. DIOPTAS: a Program for Reduction of Two-Dimensional X-Ray Diffraction Data and Data Exploration. High Pressure Res. 2015, 35 (3), 223-230.

(31) Rodriguez-Carvajal, J. Magnetic Structure Determination from Powder Diffraction Using the Program FullProf. Applied Crystallography. 2001, 30-36.

(32) Momma, K.; Izumi, F. VESTA 3 for Three-Dimensional Visualization of Crystal, Volumetric and Morphology Data. J. Appl. Crystallogr. 2011, 44, 1272-1276. 